\title{
ДАЛЬНЕВОСТОЧНЫЙ БАНК В ИРКУТСКЕ: ИЗ ИСТОРИИ КОНКУРЕНТНОЙ БОРЬБЫ В ССУДО-КРЕДИТНОЙ СФЕРЕ ПЕРИОДА НЭПА
}

В статье приводиться материал о становлении советской банковской системы в период НЭПа. На примере Иркутска анализируются особенности становления новых коммерческих банков и их взаимоотношения со структурами Государственного банка. Основное внимание уделено конкурентной борьбе на кредитном рынке Иркутска в связи с попытками зайти на него Дальневосточного банка.

Ключевые слова: Иркутск, Дальневосточный банк, иркутское отделение Государственного банка, кредитная сфера, кооперативное движение. 


\section{THE FAR EAST BANK IN IRKUTSK: FROM THE HISTORY OF COMPETITIVE STRUGGLE IN THE LOAN AND CREDIT SPHERE OF THE PERIOD OF THE NEW ECONOMIC POLICY}

The article provides material on the formation of the Soviet banking system in the period of the NEP. On the example of Irkutsk, the features of the formation of new commercial banks and their relationship with the structures of the State Bank are analyzed. The main attention is paid to competition in the credit market of Irkutsk in connection with attempts to enter the Far Eastern Bank.

Keywords: Irkutsk, Far Eastern Bank, Irkutsk branch of the State Bank, credit sector, cooperative movement.

Переход РСФСР к НЭПу привел к либерализации всей кредитной системы страны. Одним из ключевых составляющих новой политики стало создание в октябре 1921 г. Государственного банка РСФСР с капиталом в 2 трлн р. Основные его задачи заключались в восстановлении денежного обращения и контроле за его осуществлением, а также в содействии развитию промышленности, сельского хозяйства и товарооборота. Госбанк имел право банкнотной эмиссии, что служило мощным ресурсом для проведения активных операций. Все они осуществлялись исходя из принципа народно-хозяйственной целесообразности. В отличие от ранее существовавшего Народного банка он получил право исполнения кредитных функций, осуществления купли-продажи ценных бумаг, проведения вкладных, валютных, переводных и других операций. Весной 1922 г. в Новониколаевске была открыта Сибирская краевая контора Госбанка РСФСР, в подчинении которой находились отделения нескольких округов: Иркутского, Красноярского, Томского, Барнаульского, Омского, Бийского. Первым управляющим Сибирской краевой конторы был назначен А.М. Певзнер. Началось создание региональных отделений. 6 апреля 1922 г. открыло свои действия иркутское отделение Госбанка. Первые кредиты были выданы Губсоюзу и газете «Власть труда» [6, с. 454].

Наряду с вновь воссозданным Государственным банком стали возникать и другие кредитные институты. Уже в первые месяцы 1922 г. начали создаваться кредитные кооперативы и ссудосберегательные товарищества. Середина 1920-х гг. стала периодом расцвета специализированных акционерных и коммунальных банков, обслуживающих отдельные отрасли народного хозяйства. Наиболее крупными из них были Торгово-промышленный банк (Промбанк), занимавший второе место после Госбанка по объему операций, общество «Электрокредит», 
преобразованное в 1924 г. в Электробанк, Российский коммерческий банк (с 1924 г. - Внешторгбанк), Центральный сельскохозяйственный банк, Центральный коммунальный банк (Цекомбанк) и др. В регионах появились и другие акционерные и кооперативные банки для кредитования местного хозяйства. К октябрю 1925 г. в стране насчитывалось 1211 банковских учреждений (без кредитных кооперативов). Из них на долю спецбанков приходилось 752 учреждения (62 \%), тогда как Госбанк имел 459 учреждений (38 \%) [8, с. 6]. Возникшие наряду с Госбанком СССР специальные банки оказались по сути дела коммерческими. Несмотря на заявленную специализацию, все спецбанки финансировали и прочую клиентуру, в том числе частную. В тоже время, доля Госбанка в общем объеме кредитов была неизменно ведущая и имела тенденцию к дальнейшему росту. Так, в суммарном балансе сибирского кредитования доля краевой конторы Госбанка составляла 70 \%. Помимо организации и регулирования денежного обращения контора занималась привлечением свободных денежных средств предприятий, кредитованием, осуществлением расчетов, финансированием капитальных вложений государственных предприятий; а также организацией международных расчетов, операциями с иностранной валютой.

На 1 октября 1927 г. сеть кредитных учреждений в Иркутске состояла из 3-х филиалов центральных банков: Госбанка, Промбанка, Всекомбанка, одного отделения сибирского Общества сельскохозяйственного кредита и местного банка «Общество взаимного кредита». Иркутское отделение Госбанка осуществляло контроль за деятельностью всей кредитной системы в регионе, проводило ревизии балансов и отчетности. Управляющий отделением являлся по совместительству председателем губернского Совещания банков. Существующая сеть банковских учреждений в губернии вполне удовлетворяла задачам хозяйственного развития края. По своим банковским оборотам Иркутская губерния уверенно занимала второе место в Сибири, уступая только Ново-Николаевской, где находилась краевая контора Госбанка. И это несмотря на то, что по экономическим показателям она уступала таким регионам как Омская или Енисейская губернии. При этом иркутское отделение Госбанка не только полностью удовлетворяло потребности региона в кредите, но и располагало значительными излишками свободных средств для дополнительного финансирования.

Расширение кредитной системы за счет коммерческих банков на практике приводило к заметной их конкуренции с Госбанком, особенно в регионах. По мнению Сибирского краевого комитет РКП(б), рост кредитных учреждений в Сибири вызвало на местах некоторые перегибы, выразившиеся в протекционизме местных властей одного из банков в ущерб деятельности других, причем далеко не всегда в приоритете были отделения госбанка. В октябре 1926 г. Сибирская краевая контора 
Госбанка направила в филиалы письмо «О взаимоотношениях с другими банками». В нем отмечалось, что в последнее время взаимоотношения филиалов с другими банками вновь обострились и вопросы размежевания функций между Госбанком и специальными банками со всей настойчивостью выдвигаются не только на периферии, но и в центре. В этой конкурентной борьбе позиции государственного банка были более стабильны. Им взималась наименьшая ставка по учетно-кредитным обязательствам, так как он имел более дешевые пассивы. Ставки же спецбанков были на 1-3 \% выше [1, с. 120]. В стремлении увеличить клиентуру региональные отделения Госбанка использовали различные методы. Иркутское отделение развернуло настоящую борьбу с Промбанком за крупные торгово-промышленные заведения губернии. Так, иркутское отделение Чаеуправления по разрешению своего правления имело право держать резерв средств до 200 тыс. р. для оплаты акцизов и таможенных сборов за чай, поступающий из-за границы. До 1925 г. эти деньги держали на счетах Промбанка, так как он представлял 8 \% годовых, но когда отделение Госбанка снизило ставку до 7 \% более выгодно стало работать с ним [3, л. 23]. Точно так же иркутскому отделению удалось привлечь ресурсы крупнейшего сибирского предприятия «Черембастрест» который традиционно обслуживался в Промбанке, более того, был его акционером. Как отмечал управляющий иркутским отделением Госбанка И.Я. Рабкин: «Мы полагаем, что отношения Госбанка и Черембастреста, в свое время выразившиеся в широком кредитовании его на весьма выгодных условиях, дает Госбанку право рассчитывать на то, что и Черембастрест сохранит перед ним минимальные обязанности, выражающиеся в резервировании на текущем счету у последнего своих свободных средств» [3, л. 24]. В итоге до 30 \% оборота угольного треста стал обслуживать Госбанк. Пользуясь правом регулятора кредитной сферы, иркутское отделение Госбанка в начале 1927 г. вообще инициировало вопрос о закрытии на своей территории отделения Промбанка. Это вполне соответствовало политики Центра, вновь пытающегося сосредоточить все кредитование начавшейся индустриализации страны в одних руках. Приветствуя закрытие филиалов Промбанка в Сибири Краевая контора отмечала ведущую роль государственного кредитования. В 1926 г., по ее данным общий баланс всей банковской сферы составил 144,3 млн р., из которых на Госбанк приходилось 71,8 млн р. (50 \%), а на Промбанк всего 13,8 млн (9,6 \%) [4, д. 6, л. 21]. По Иркутскому отделению ситуация была следующей: из общего банковского баланса в 8,9 млн р. на Госбанк приходилось 4 млн (45 \%), на Промбанк - 1,5 млн р. (26,6 \%). Клиентами Промбанка в Иркутске были по преимуществу предприятия централизованной торговли, с которыми органы Госбанка не работали из-за отсутствия выделенного кредита. В результате такого анализа Краевая контора Госбанка пришла к выводу, что сохранение сибирских 
филиалов Промбанка в условиях режима экономии и рационализации банковской работы не целесообразно. В результате закрытия филиала в Иркутске вся его клиентура отошла к иркутскому отделению Госбанка. По подсчетам его специалистов на удовлетворение ее кредитами потребуется дополнительно около 1,7 млн р. [4, д. 6, л. 75].

Не менее негативные высказывания звучали и в отношении других коммерческих банков. Сложные взаимоотношения были у Госбанка с Всекомбанком и его политикой в отношении инвестиций в развитие кооперативного движения. Активное вмешательство Госбанка в дела кооперации вызывало озабоченность у различных кооперативных организаций и союзов. На специальном совещании акционеров иркутского отделения Всекобанка решительной критика подверглось стремление Госбанка монополизировать кредитование кооперации и было предложено сосредоточить кредитование кооперативной ссреры только в профильных банковских учреждениях. Вскоре после совещания в газете «Власть труда» появилась статья члена Коопсовета Григорьева, в которой обосновывалось требование передачи всей кооперативной клиентуры и кредитов Всекомбанку [2]. Иркутское отделение неоднократно критиковало «Общество взаимного кредита» за преимущественное кредитование крупной частной торговли при ограничении кредита для мелких кустарей и розничных торговцев. В работе кредитной организации вообще было много нарушений. Широко практиковалось подтоварное кредитование в крупных размерах, что способствовало расширению спекулятивных связей в торговле. При распределении прибылей члены Правления выдавали себе крупные вознаграждения. Зачастую кредитование компаньонов одной и той же фрирмы производилось на ее лицевой счет, а каждому из пайщиков по отдельности, благодаря чему сумма кредитования значительно превышала выделяемый размер кредита $[4$, д. 7, л. 3]. В качестве решительного воздействия на политику «Общества» использовался банковский механизм. Иркутское отделение аннулировало выделенный ему кредит на 10 тыс. р. и потребовало немедленно погасить задолженность. А вскоре в отношении этой организации была назначена очередная ревизия.

Следует отметить, что отношения между краевой конторой и иркутским отделением были не самые хорошие. Вышестоящая структура не раз ставила на вид иркутскому управляющему излишнюю самостоятельность в высказываниях и действиях, предлагая «решительным образом... усвоить соответствующий тон в переписке с Конторой» [3, л. 20]. Сохранившиеся документы свидетельствуют, что управляющему местным отделением приходилось лавировать между позицией своего ведомства и губернскими партийными органами. Настоящая полемика разразилась по поводу открытия в Иркутске отделения Дальневосточного акционерного банка (Дальбанка), встретившее резко негативное 
отношение со стороны Сибирской краевой конторы. Несколько слов следует сказать о самом Дальбанке, история которого интересна сама по себе. Он был учрежден в марте 1922 г. как центральный банк Дальневосточной республики (ДВР) и осуществлял с другими финансовыми учреждениями регулирование денежного обращения. Валютная политика Дальбанка была нацелена на сохранение и увеличение монетного фонда и обеспечение устойчивости денежной единицы в республики. Банк регулировал бюджетное равновесие, систему платежного баланса и пытался удержать отток из страны золотых и серебряных монет. Дальневосточный банк являлся эмиссионным банком ДВР и во внешнеэкономической фринансовой политике придерживался позиции концентрации в своих руках операций по расчетам с заграницей с целью устранить и сократить утечку золотой монеты с территории страны, связанную с пассивностью торгового баланса. Он старался покрывать задолженность по расчетам с зарубежными странами исключительно в золотых слитках, но, вместе с тем, принимал меры к привлечению золотой монеты из-за границы. Дальневосточный банк был акционерным финансово-кредитным учреждением. Учредителями его были: правительство ДВР, Дальневосточное отделение Центросоюза и Читинская торгово-промышленная палата [5, с. 424]. При этом правительству республики принадлежал контрольный пакет в 55 акций. Устав Банка был утвержден 24 марта 1923 г. В соответствие с ним капитал Банка был определен в 2 млн р., разбитых на 40 тыс. акций по 50 р., но впоследствии был увеличен до 3 млн р. Одной из отличительных черт Банка являлось предоставление ему права на устройство золотоплавилен, лабораторий для опробования золота, опытно-показательных станций по прочим (горной, лесной) отраслям промышленности.

С ноября 1922 г. после присоединения ДВР к РСФСР функции Дальневосточного банка были изменены. Он стал заниматься в основном краткосрочным кредитованием золотодобывающей промышленности, промыслов, торговли, а также специализировался в банковском обслуживании торговли с Китаем. Его центральная контора была перенесена из Читы в Хабаровск. Если в ДВР банк был чисто расчетным, то став российским, он начинает проводить активные операции. Нужно отметить, что из средств, находившихся в обороте, только 30 \% были его собственными капиталами, а остальные привлеченными, что полностью соответствовало природе коммерческих банков, в основном использующих депозиты клиентуры. Основными акционерами и клиентами банка были предприятия госсектора [1, с. 119].

Кредитование дальневосточной золотопромышленности продолжало оставаться приоритетным для Дальбанка. В нем был создан специальный «золотой» отдел. Только за один 1923 г. его операции, связанные с добычей и закупкой золота выросли на 70,6 \%. Дальбанк, таким обра- 
зом, был в эти годы одним из крупнейших кредитных учреждений на Востоке страны. Он, в частности, принял самое непосредственное участие в организации Монгольского торгово-промышленного банка [1, с. 119]. Кроме того, банк с самого начала своего существования принимал активное участие в кредитовании экспортно-импортных операций в Маньчжурии и Китае. В литературе его часто путает с Дальневосточным банком в Харбине, считая, что последний являлся его филиалом. Как отмечают новейшие исследования это были разные банки, активно сотрудничающие друг с другом [7, с. 598]. Такая ситуация во многом была связана с запутанной системой учреждения и соподчинения банков внутри советской банковской системы в 1920-е гг. Волею случая, в Харбине возникло почти одновременно два совершенно разных банка, имевшие сходное название. В конце 1922 г. группой крупных предпринимателей во главе с Сосниными, Скидельскими, Фризерами был учрежден «Дальневосточный еврейский коммерческий банк». Спустя год в Харбине уже Советской властью был организован Дальневосточный банк, как советский акционерный загранбанк на китайском уставе и под китайской юрисдикцией. Управляющим его вначале были Н.Н. Ромм, а затем С.М. Шапиро. На банк было возложено финансовое обслуживание КВЖД и клиентуры, связанной с советско-китайской торговлей в Китае. Клиентами банка были также многочисленные советские граждане в Китае. Известно, что банк занимался распространением советских займов среди русской диаспоры Харбина и в Маньчжурии в целом [7, с. 598].

Кроме золотых операций, Дальбанк в Хабаровске занимался обычными банковскими операциями, кредитуя местные торговлю и промышленность. В течение 1925/26 г. в деятельности Банка произошли некоторые изменения. При содействии Наркомфина СССР в результате двух дополнительных выпусков акций до 5 млн р. был увеличен его капитал. В 1925 г. при банке был организован коммунальный отдел с целью долгосрочного (до 5 лет) кредитования коммунальных хозяйств, что позволило приступить к кредитованию жилищного и коммунального строительства в городах Дальневосточного региона [5, с. 424]. На 1 октября 1925 г. основной капитал банка составлял 5 млн р. при годовом балансе около 40 млн р. На учетно-ссудные операции приходилось 11 млн р., текущие счета, не считая вклада на золотые операции, составляли около 8 млн р. Прибыль за 1925 операционный год составила 945 тыс. р., а дивиденд - 12 \% [7, с. 597]. К моменту прихода в Иркутск сеть банка состояла, не считая правления в Хабаровске, из 8 филиалов: Читинской и Владивостокской конторы, отделений в Благовещенске, Верхнеудинске, Николаевске-на-Амуре, Петропавловске-на-Камчатке и Сретенского агентства. Баланс банка вырос с 4,4 млн р. в 1923 г. до 32,1 млн р. на 1 октября 1927 г. При этом следует отметить, что кредитование золотопромышленности, а равно организаций, скупающих золото, составляло 
до 32 \% в общей сумме всех учетно-ссудных операций. В дальнейшем после кредитной рефрормы в СССР в 1930-1932 гг. он стал заниматься фринансированием капитального строительства предприятий и организаций местного подчинения и был реорганизован в Дальневосточный коммунальный банк, а незадолго да Великой отечественной войны прекратил свое существование.

Руководство Иркутской губернией считало, что существующая в регионе кредитная система не вполне удовлетворяет потребности народного хозяйства. В начале 1925 г. Губисполком планировал открыть в Иркутске городской (коммунальный) банк, а когда это не удалось, воспользовался предложением Дальбанка [4, д. 4, л. 6]. Основные причины были связаны с предполагаемой реорганизацией региона в Лено-Байкальскую область. Помимо заинтересованности в расширении кредитных услуг, считалось, что сотрудничество с Дальбанком даст возможность для продвижения местной промышленности и торговли на рынки Монголии и Дальнего Востока. По мнению И.Я. Рабкина, эта позиция губернских властей не соответствовала действительности. Для развития операций в Монголии правление Госбанка СССР отпустило Краевой конторе только в третьем квартале 1925 г. капитал в 1,5 млн р., в то время как у Дальбанка никаких отделений в соседней стране вообще не было. Кроме того, на Дальнем Востоке Госбанк также имел значительную сеть своих филиалов, поэтому необходимости в привлечении других банков для выхода на новые территории не было. «К сожалению, - писал управляющий иркутским отделением, - приходится отметить, что ажиотаж, созданный вокруг открытия Отделения Дальбанка в Иркутске, совершенно не отвечает степени выгодности Дальбанка для Иркутской губернии» [4, д. 4, л. 10]. Он считал, что Дальбанк стремился на территорию Сибири не для расширения кредитной деятельности. Собственных капиталов у него было всего около 3 млн р., меньше чем располагало одно только иркутское отделение. Интерес у него был связан в привлечении пассивов и оперировании ими. Первые шаги отделения Дальбанка в Иркутске свидетельствовали об этом. На 1 сентября 1925 г. им было собрано текущих счетов на 188 тыс. и выдано кредитов на 185 тыс. р. [4, д. 4, л. 10].

Открытие отделения Дальбанка в Иркутске с капиталом в 30 тыс. червонцев вызвало резкие трения не только между банковскими конторами, но и между Сибревкомом и Иркутским губисполкомом, что привело к заметному сокращению кредитов местной промышленности. Сложившаяся ситуация была крайне невыгодна иркутскому отделению, как в сокращении пассивов, так и в ухудшении отношений с губернской властью. Иркутскому отделению пришлось исполнять распоряжения Краевой конторы о закрытии кредитов ряду местных организаций, что поставило в сложное положение Ирторгпром [4, д. 4, л. 10 об.]. После различных взаимных упреков между краевым и губернским отделениями Госбанка, 
с одной стороны, и руководителями Иркутской губернии, с другой, было решено временно оставить филиал Дальбанка в Иркутске. Такой накал страстей был тем более странен, что правление Госбанка СССР владело более 50 \% акций Дальбанка, т.е. являлось его фрактическим хозяином [3, л. 39]. Компромисс продолжался недолго и уже в марте 1927 г. последовало распоряжение о закрытии отделения Дальбанка в Иркутске. Ситуация вокруг Дальбанка не только отражает конкурентную борьбу за кредиты и клиентов между банками, но и отражает тенденцию к укреплению монопольного положения государственного банка в ссудно-кредитной сфрере. В конце 1920-х гг. с переходом от НЭПа к построению социализма началось постепенное свертывание частного предпринимательства и рыночного хозяйства. В этих условиях вновь появилась идея «единого банка», как ведущего органа осуществления кредитной политики в стране. Постановлением ЦИК и СНК СССР от 15 июня 1927 г. «О принципах построения кредитной системы» усиливалось централизованное руководство всеми кредитными учреждениями со стороны Государственного банка СССР. Госбанк должен был наблюдать за деятельностью остальных кредитных учреждений в соответствии с правительственными директивами в области кредитной политики. Спецбанки должны были хранить свободные средства и кредитоваться только в Госбанке, которому предоставлялось право участвовать в их советах и ревизионных органах. Кроме того, Госбанк должен был увеличить свою долю в акционерных капиталах спецбанков. В следующем году на Госбанк была возложена обязанность кассового исполнения госбюджета, что позволило сосредоточить в нем кассовые операции социалистического хозяйства.

\section{Список использованной литературы и источников}

1. Баженов А. Е. Развитие банковской системы на Дальнем Востоке России в 1920-х гг. / А. Е. Баженов // Власть. - 2012. - № 8. - С. 118-121.

2. Григорьев. Госбанк, Сельхозбанк или Всекомбанк / Григорьев // Власть труда. - 1927. - № 145.

3. Государственный архив Иркутской области (ГАИО). - Ф. Р-61. Оп. 1. - Д. 5.

4. ГАИО. - Ф. Р-61. - Оп. 2.

5. Куперман Я. Дальне-Восточный банк / Я. Куперман // Финансовая энциклопедия / под общ. ред. Г. Я. Сокольникова. - 2-е изд. - М. ; Л. : Гос. изд-во, 1927. -580 с.

6. Романов Н. С. Летопись города Иркутска за 1902-1924 гг. / Н. С. Романов / сост. Н. В. Каликаускене. - Иркутск : Вост.- Сиб. кн. изд-во, 1994. - 560 с.

7. Саломатина С. А. Российские и советские банки в странах Среднего и Дальнего Востока, 1890-е - 1920-е гг.: трансформация имперских традиций / С. А. Саломатина // Экономическая история: Ежегодник. 2013. - М. : Политическая энциклопедия, 2014. - С. 568-624.

8. Смольянинова Е. Н. Организация деятельности Центрального банка РФ: учеб. пособие / Е. Н. Смольянинова. - Владивосток : Изд-во ВГУЭС, 2005. — 95 с. 


\section{Информация об авторе}

Шахеров Вадим Петрович - доктор исторических наук, профессор кафедры истории России, Иркутский государственный университет, 664025, г. Иркутск, ул. Чкалова, 2; e-mail: wodalis@yandex.ru

\section{Author}

Vadim P. Shaherov - Doctor of History, Professor, Department of Russia History, Irkutsk State University, 2, Chkalov St., 664025, Irkutsk, Russia; e-mail: wodalis@yandex.ru 